ИЗВЕСТИЯ АКАДЕМИИ НАУК ЭСТОНСКОП ССР. ТОМ 32. ГЕОЛОГИЯ. 1983, Na 2

\title{
О ДРЕВНИХ ПОГРЕБЕННЫХ ВРЕЗАХ В ТАЛЛИНЕ
}

Хозяйственно-питьевое водоснабжение в Таллине обеспечивается в основном поверхностными водами. На долю подземных вод приходится всего лишь около $1 / 3$ водопотребления. Наибольшее значение при этом имеет кембро-вендский комплекс, который в настоящее время дает примерно $3 / 4$ всех подземных вод, используемых в Таллине (около 80000 м $^{3}$ в сутки; Belkin, Savitski, 1978).

Немаловажное значение в обеспечении города хозяйственно-питьевой водой имеют также четвертичные отложения древних врезов и флювиогляциальных дельт Нымме и Мяннику. В то же время глубоко врезанные в коренные породы долины и долинообразные понижения сверху недостаточно защищены малопроницаемыми суглинистыми моренами и озерно-ледниковыми отложениями и поэтому подчетвертичные водоносные горизонты легко доступны загрязнению. Таллин, как известно, район концентрации различных отраслей промышленности - машинной, металлообрабатывающей, пищевой, целлюлозно-бумажной, химической и текстильной, которые дают около $45 \%$ всей промышленной продукции республикн. Многие из предприятий расположены или над древними врезами, или в их непосредственной близости. К промышленным стокам прнбавляются еще коммунальные. Наибольшую опасность здесь представляют маслохранилища мелких котельных, где неоднократно были обнаружены аварийные сбросы жидкого топлива. Если к сказанному добавить, что предвидится хорошая перспектива создания искусственных запасов подземных вод на базе погребенных долин путем перевода части поверхностного стока в подземный (Tšeban, 1978), то актуальность уточнения расположения и строения древних врезов не вызывает сомнений.

Несмотря на длительную историю исследования и наличие множества скважин, погребенные врезы Таллина до сих пор еще очень слабо изучены: нет ни надежно установленной стратиграфической последовательности слоев, ни каких-либо обобщающих сведений о гранулометрическом и литолого-минеральном составе отложений. Нет даже единого мнения о количестве и названиях этих долин, не говоря уже об их точном расположении и морфологии. Весьма скудны также данные о продолжении погребенных врезов вне административных границ Таллина.

Вопросы строения и расположения долин затрагивались в некоторых рукописных отчетах по гидрогеологии и инженерной геологии города (авторы А. Верте, Р. Арбейтер, В. Белкин, Л. Валлнер, А. Вийганд, А. Вило, Х. Лийвранд, К. Стумбур и др.), но и этот материал является отрывочным и противоречивым.

Э. Чебан (Tšeban, 1978) насчитывает в Таллине четыре погребенных вреза: Мустамяэ-Пелгуранд, Харку, Центральный и Мяхе. Несколько раньше С. Кюннапуу и А. Раукас (Künnapuu, Raukas, 1976) отмечали три палеовреза: один глубиной около 100 м идет, по их мнению, от западного берега оз. Юлемисте в Қоплиский залив, другой, менее глубокий, - 

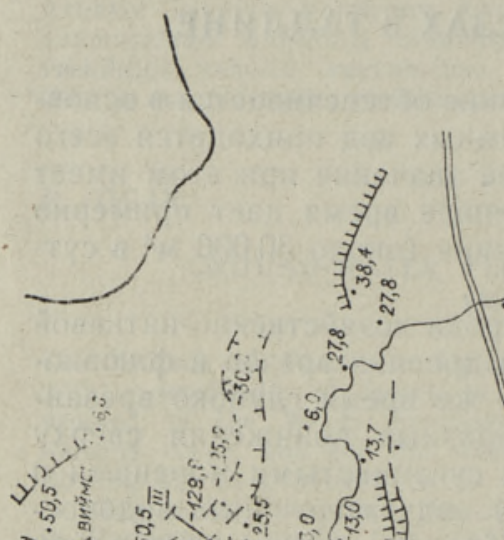

-

nim

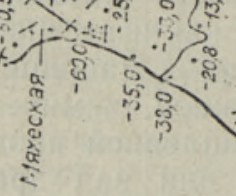


между Тоомпеа и Ласнамяэ в Таллинский залив и третий, самый глубокий (около 145 м), - через оз. Харку в Какумяэский залив. Были высказаны предположения (Raukas, Rähni, 1974), что одну из этих долин можно проследить до города от Паункюла, а другую - от Кийза. Э. Таваст (1981) допуокает, что одна из погребенных долин Таллина начинается в окрестностях Янеда. В начале она идет в субширотном направлении на 3 С 3 , а затем поворачивает на север. После пересечения глинта она раздваивается: один рукав направляется в современный Коплиский залив, а другой - в Какумяэский. Расположение этого вреза установлено c. помощью отдельных, расположенных далеко друг от друга скважин. Вполне возможно, что эти скважины маркируют не долину субширотного направления, а верховья еще не установленных долин северного или северо-западного простирания. Все обнаруженные в Таллине долины продолжаются к северу на дне Финского залива, где они в дочетвертичное время впадали в долину Пра-Невы (Квасов, 1975).

На составленной нами карте рельефа коренных пород Таллина и его окрестностей (Кюннапуу и др., 1981) показаны девять долин и долинообразных понижений, которые с учетом их разной глубины и морфологии, а также незакономерной конфигурации в плане, явно имеют неодинаковый возраст и генезис. Они были названы нами Харкуской, Лиллекюлаской, Қадриоргской, Пиритаской, Саку-Ныммеской, Саку-Вяэнаской, Набала-Сакуской, Саусти-Раудалуской и Раэской. Только четыре первых из них (Харкуская, Лиллекюлаская (Коплиская, МустамяэПелгурандская), Кадриоргская (Центральная) и Пиритаская (Мяхеская)) - истинные долины (рис. 1) и могли существовать уже в дочетвертичное время. Остальные являются плоскими и маловыразительными в рельефе и имеют. по всей вероятности, экзарационный генезис. Глубина таких долинообразных понижений при ширине $1,5-3,5$, км обычно порядка 10 м. Возможно, что их отдельные отрезки являются продолжением нстинных речных долин, неузнаваемо преобразованных ледниками - нельзя забывать, что экзарацией с Виру-Харьюского плато снесен слой карбонатных коренных пород мощностью в несколько десятков метров. Так, Саку-Ныммеское понижение может служить продолжением Харкуской долины и Раэская долина - Кадриоргской, хотя неоспоримых фактов для подтверждения такого заключения нет. Очень сложно и еще невыяснено соотношение Харкуской и Лиллекюлаской долин в предглинтовой области. На схемах обычно указывается слияние их перед глинтом северо-восточнее кладбища Рахумяэ и перекрестка ул. Рахумяэ теэ и Тервизе. Коренные породы в этом месте, по данным о нескольких скважинах, находятся $11-18$ м ниже уровня моря. Но такое разветвление рек вниз по течению, согласно флювиальной теории, маловероятно. Скорее всего эти долины в дочетвертичное время были изолированы друг от друга и их соединение, если это действительно имеет место, произошло лишь благодаря последуюшей ледниковой эрозии.

Проанализируем, какова могла быть конфигурация первичной дочетвертичной речной сети в пределах города. По имеющимся данным, палеорека Харку меридионального простирания пересекала глинт близ замка Глена, а затем поворачивала через современное оз. Харку на северозапад. Ее можно проследить по скважинам на Эхитаяте теэ 5 (Политехнический институт) (-69,3 м), на территории Мустамяэской поликлиники (Эхитаяте теэ 27) (-43,6 м), севернее перекрестка Мустамяэ теэ и шоссе Палдиски $(-40,0$ м), на южном берегу оз. Харку $(-30,9$ м), на северо-западном берегу озера $(-82,4$ м $)$, северо-западнее от места пересечения Тискреского ручья и шоссе Раннамыйза $(-143,2$ м) и западнее устья Тиокреского ручья $(-100,7$ м). Харкуская долина проходит между глинтом и коренным возвышением. Какумяэ. Ширина ее севернее о3. Харку при глубине около 100 м составляет примерно 800 м. Буровые 

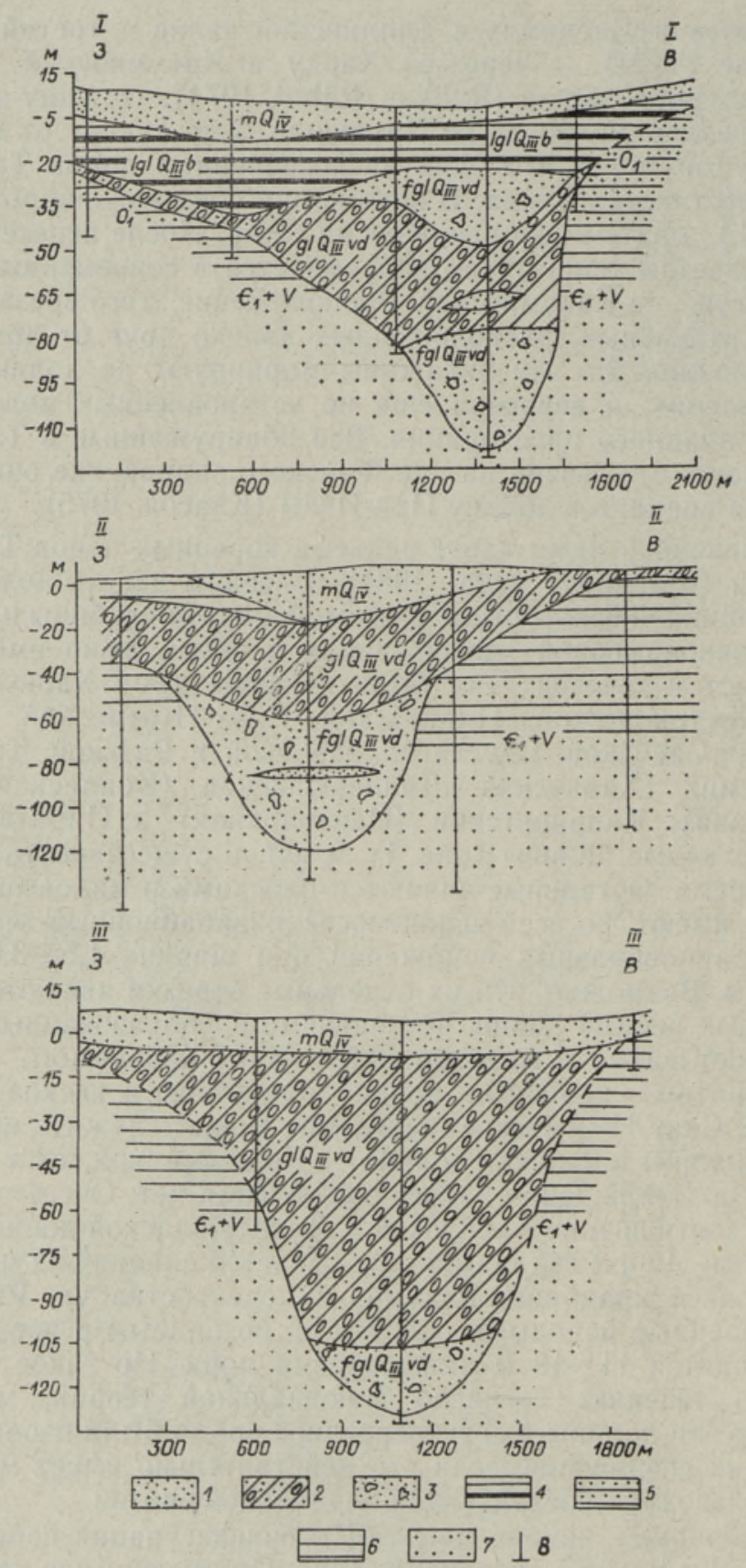

Рис. 2. Геологическое строение Харкуской (I-I), Лиллекюлаской (II-II) и Мяхеской (III-III) погребенных врезов: 1 - песок; 2 - морена; 3 - гравийно-галечные отложения; 4 - ленточные глины; 5 - алевролит; 6 глина; 7 - песчаник; 8 - буровые скважины.

Расположение разрезов см. рис. 1 .

скважины расположены в ней незакономерно и по их данным очень трудно судить, каковы характер склонов и дно долины, поперечное и продольное сечение и т. д. Можно предположить, что поперечный профиль 
долины имеет пологую $\mathrm{V}$-образную форму, склоны изменчивые. Восточный склон долины более крутой, нежели западный (рис. 2, I).

По всей вероятности, Саку-Ныммеское долинообразное понижение было продолжением Харкуской долниы на Виру-Харьюском плато. Это понижение глубиной $10-15$ м прослеживается от Саку до Нымме по нескольким скважинам. Понижение располагается между коренными возвышениями.Пяэскюла и Мяннику. Ориентировано оно с юга на север. При небольшой глубине ширина понижения составляет в южной части v Саку около 2,0 км, а в северной части в районе Нымме и Хийу около 1,5 км. Поперечное сечение его невыразительно.

Но не исключено, что продолжением Харкуской долины на плато является не Саку-Ныммеское, а Саусти-Раудалуское долинообразное понижение, которое можно проследить от Раудалу близ Вильяндиского шоссе. Это довольно широкое понижение $(1,5-2,5$ км) при относительно малой глубине (15-20 м) расположено в ордовикских породах. Дно его находится у Раудалу 13.9 м над уровнем моря, у Раку 13,0 м, к югозападv от оз. Юлемисте 7,8 м ниже уровня моря и при пересечении глинта на Мяннику теэ 12 уже 26,6 м ниже уровня моря. После пересечения глинта понижение еще углубляется и, видимо, продолжается в предглинтовой области не в виде Харкуской, а в виле Лиллекюлаской долины северного простирания. Последняя эродирована в легкоразрабатываемые песчаники и глины венда и кембрия. Эта долина расположена на Лиллекюлаской низине между коренными возвышениями Какумяэским и Вескимяэским (на северо-западе) и Коплиским и Центральным (на севепо-востоке). Дно толины находится на территории железнодорожной больнишы на глубине -82.0 м, на ул. Мути $23-61.2$ м. на перекрестке улиц Вырсе и Кянну -57.1 м. в районе Катака теэ ло -86.6 м, на vл. Энлла $77-81.0$ м. на шоссе Паллиски -123.4 м. там же (ИнФекшионная больниша) -102.0 м и междv ипподромом и берегом моря -107.2 м. Лиллекюлаская полина шире Харкиской (около 1.0 км), но не менее глубокая (рис. 2, II). По имеющимся данным, поперечный профиль долины симметричен, местами слабо ступенчат.

Северо-восточнее от Центрального возвышения расположена Кадриоргская (Центральная, по Э. Чебан; Tšeban, 1978) долина. Она начинается от оз. Юлемисте, где кровля в котловине находится на высоте 9.0 м (Doss, 1912). вначале направляется на северо-запад до Таллинской республиканской больницы, а отсюда при глубине $-52,5$ м поворачивает на север и ССВ. До порта она прослеживается по отдельным скважинам, которые, вилимо, расположены не в самой глубокой части, а на склонах лолины. Дно ее прослеживается на ул. Херне $11(-29.5$ м) и на ул. Маакри $27(-35,0$ м). На перекрестке ул. Реймани и Нарвского шоссе (на территории ЭРСПО) дно долины установлено на глубине $-80,7$ м. Глубина этой долины, видимо, не достигает 100 м, ширина в пайоне vл. Кингиссепа составляет $300-400$ м, а близ Нарвского шоссе $500-600$ м. По имеюшимся геологическим данным, можно предполагать, что склоны долины довольно пологие и в целом она имеет корытообразную форму.

В Пиритаской глинтовой бухте, где абсолютные отметки коренных пород колеблются от -25 до -38 м, расположена Пиритаская (Мяхеская) древняя долина (рис. 2, III). Простирание вреза северо-западное. Долина обнаружена в ряде мест в Меривялья и Мяхе. Дно ее достигает близ ул. Меривялья $-129,8$ м, на ул. Кеэру $11-125,2$ м. Продолжение лолины на Виру-Харьюском плато окончательно не выявлено. Между Лагеди и Иру, близ Ленинградского шоссе в коренных породах установлено понижение глубиной $10-15 \mathrm{~m}$. Не исключено, что долина вообще не заходит на плато, а окружает Виймсиское возвышение.

О возрасте немых терригенных толщ, заполняющих долины, ввиду 
отсутствия надежно датированных межледниковых отложений судить трудно. Чаще всего в строении долины встречается одна морена серого цвета, которая над- или подстилается флювиогляциальными гравийногалечными и гравийно-песчаными отложениями. Возраст морены и генетически связанных с ней водноледниковых отложений - верхневалдайский. Лишь изредка (например, на территории железнодорожной больницы) в долинах прсслежнвается более древняя морена. Она также серого цвета и возраст ее либо нижневалдайский, либо московский. Более древних отложений здесь пока не обнаружено. В таблице надморенные флювиогляциальные отложения рассматриваются как верхневалдайские, а подморенные - условно как нижневалдайские. Надморенные флювиогляциальные отложения нередко покрываются озерно-ледниковыми алевритами и ленточными глинами заключительных стадий отступления ледника последнего оледенения. Судя по строению Мянникуской дельты, где под флювиогляциальными отложениями местами установлены озерно-ледниковые (Раукас, Ряхни, 1966), здесь, видимо, присутствуют водноледниковые отложения двух стадий или фаз - пандивереской и паливереской.

Плейстоценовые ледниковые и водноледниковые отложения покрываются отложениями Балтийского моря, озерно-болотными отложениями и техногенными грунтами. Мощность голоценовых морских отложений достигает 18-20 м (перед Домом быта), а техногенных - 8 м (в центральной части города).

Қак выявляется из таблицы, где дано соотношение отложений различных генетическнх типов в разных долинах г. Таллина, по характеру заполняющих отложений рассматриваемые долины сильно отличаются. Но отметим, что по мере накопления новых данных сведения, представленные нами в таблище, могут существенно изменяться.

По предварительным данным, в Харкуской и Мяхеской долинах сильно превалирует морена последнего оледенения, в Лиллекюлаской долине ведущее место приналлежит флювиогляциальным отложениям, а в Кадриоргской - лимногляциальным. Техногенные отложения наиболее широко представлены в пересекающих центральную часть города Кадриоргской и Лиллекюлаской долинах. Голоценовые, в основном морские отложения, за исключением Мяхеской долины, распространяются более или менее равномерно. Аллювиальные отложения в погребенных долинах встречаются редко (в Мяхеской долине к югу от городиша Иру, к западу от оз. Харку). Важно также отметить, что характер отложений может сильно различаться даже в близлежащих скважинах (см. рис. 2, I), что уменьшает генетическое и прикладное значение представленных средних показателей.

Отсутствие или очень небольшое содержание нижне- и среднечетвер-

Соотношение отложений разных генетических типов в погребенных долинах предглинтовой области, \%

\begin{tabular}{|c|c|c|c|c|c|c|c|}
\hline Долина & $\geqq$ & $\begin{array}{l}\geq \\
E \\
\pm \\
\pm\end{array}$ & $\sum_{\infty}^{\infty}$ & 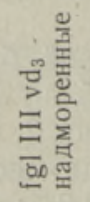 & 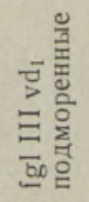 & 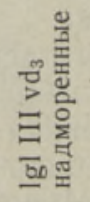 & $\vec{\Xi}_{\bar{\Xi}}^{\vec{\Xi}}=$ \\
\hline $\begin{array}{l}\text { Харкуская } \\
\text { Лиллекюлаская } \\
\text { Кадриоргская } \\
\text { Мяхеская }\end{array}$ & $\begin{array}{l}0,5 \\
0,9 \\
8,3 \\
0,2\end{array}$ & $\begin{array}{l}22,4 \\
18,4 \\
24,2 \\
16,1\end{array}$ & $\begin{array}{l}42,3 \\
22,3 \\
16,4 \\
56,9\end{array}$ & $\begin{array}{r}13,8 \\
43,4 \\
3,2 \\
2,2\end{array}$ & $\begin{array}{r}6,6 \\
8,9 \\
5,6 \\
20,4\end{array}$ & $\begin{array}{r}14,3 \\
5,9 \\
42,3 \\
4,2\end{array}$ & $\begin{array}{c}0,1 \\
0,2 \\
? \\
?\end{array}$ \\
\hline
\end{tabular}


тичных отложений в изученных палеоврезах объясняется сильным воздействием позднеплейстоценовых ледников, которые унесли'и ассимилировали более древние отложения. Ледники и их талые воды, несомненно, углубляли и расширяли имеющиеся здесь речные долины, особенно в связи с тем, что простирание их в основном совпало с направлением движения позднеплейстоценовых ледников (Raukas, 1961).

Поэтому, хотя первоначальный генезис рассматриваемых палеоврезов был флювиальным, в современном виде они уже не речные долины, а ложбины ледникового выпахивания и размыва.

\section{ЛИТЕРАТУ Р А}

Квасов Д. Д. Позднечетвертичная история крупных озер и внутренних морей Восточной Европы. Л., 1975.

Кюннапуу С., Раукас А., Таваст Э. О рельефе коренных пород г. Таллина. - Изв. АН ЭССР. Геол., $1981,30,167-172$.

Раукас А. В., Ряхни Э. Э. К вопросу об отступании материкового льда последнего оледенения с территории Эстонской ССР. - Ежегодник Эстонского географического об-ва 1964/65. Таллин, $1966,5-17$.

Таваст Э. О развитии дочетвертичных и плейстоценовых долин Эстонин. - В кн.: Исследование развития скандинавского ледннкового покрова на территории СССР. Апатиты, 1981, 35-44.

Belkin, V., Savitski, L. Tallinna põhjaveega varustamise võimalustest. - Rmt.: Pōhjavee kasutamisest ja laitsest Eesti NSV-s. Tallinn, 1978, 20-22.

Doss, B. Der geologische Aufbau der Ostseeprovinzen, - In: Adolf Richters Baltische Verkehrs- und Adressbücher. T. 3. Estland. Riga, 1913, S. IV-V.

Künnapuu, A., Raukas, S. Pinnamood ja pinnakate. - Rmt.: Tallinna ajalugu, I. Tallinn, 1976, 20-36.

Raukas, A. Mandrijää liikumisest Eestis. - Eesti Loodus, 1961, 5, 259-264.

Raukas, A., Rähni, E. Pinnavormid. - Rmt.: Harju rajoonis. Kodu-uurijate seminarkokkutulek. Tallinn, 1974, 43-46.

Tšeban, E. Põhjavee tehisvaru loomise võimalustest Eestis. - Rmt.: Põhjavee kasutamisest ja kaitsest Eesti NSV-s. Tallinn, 1978, 30-43.

\author{
Институт геологии \\ Академии наук Эстонской ССР
}

Поступила в редакцию

5/IV 1982

Elvi TAVAST, A. RAUKAS, S. KONNAPUU

\section{TALLINNA VANADEST MATTUNUD VAGUMUSTEST}

Tallinnas on aluspõhja lõikunud neli sügavat orgu (Harku, Lilleküla, Kadrioru ja Mähe) ja viis orutaolist vagumust. Esimesed on liustike ja nende sulamisvete poolt tugevasti ümberkujundatud kvaternaarieelsed jōeorud, viimased liustike kulutusnõod. Orud on täitunud valdavalt ülemvaldai ja holotseeni setetega, kusjuures nende suhtvahekorrad on erinevad. Orgudel on suur tähtsus linna veevarustuses.

\section{Elvi TAVAST; A. RAUKAS, S. KONNAPUU}

\section{ANCIENT BURIED VALLEYS IN TALLINN}

The area of Tallinn contains four buried valleys (thoșe of Harku, Lilleküla, Kadriorg, Mähe) that are deeply cut into the bedrock surface, and five valley-like depressions.

The first-mentioned ones are ancient river-valleys which were formed already in the Pre-Quaternary and subsequently reshaped by giaciers and their meltwaters. The depressions have been formed aś a result of exaration. The ancient valleys are mainly filled with upper-Valdaian and Holocene deposits, which are present in extremely different amounts (see Table). The ancient valleys also contain underground water of a good quality, which can be used in the water supply of the town as well as in industry. 